\title{
Patient Outcomes and Cerebral Infarction after Ruptured Anterior Communicating Artery Aneurysm Treatment
}

\author{
(D).J. Heit, (D) R.L. Ball, DN.A. Telischak, DH.M. Do, (D)R.L. Dodd, (D) G.K. Steinberg, (DS.D. Chang, (D) M. Wintermark, and (D) M.P. Marks
}

\begin{abstract}
BACKGROUND AND PURPOSE: Anterior communicating artery aneurysm rupture and treatment is associated with high rates of dependency, which are more severe after clipping compared with coiling. To determine whether ischemic injury might account for these differences, we characterized cerebral infarction burden, infarction patterns, and patient outcomes after surgical or endovascular treatment of ruptured anterior communicating artery aneurysms.
\end{abstract}

MATERIALS AND METHODS: We performed a retrospective cohort study of consecutive patients with ruptured anterior communicating artery aneurysms. Patient data and neuroimaging studies were reviewed. A propensity score for outcome measures was calculated to account for the nonrandom assignment to treatment. Primary outcome was the frequency of frontal lobe and striatum ischemic injury. Secondary outcomes were patient mortality and clinical outcome at discharge and at 3 months.

RESULTS: Coiled patients were older (median, 55 versus 50 years; $P=.03$ ), presented with a worse clinical status $(60 \%$ with Hunt and Hess Score $>2$ versus $34 \%$ in clipped patients; $P=.02)$, had a higher modified Fisher grade $(P=.01)$, and were more likely to present with intraventricular hemorrhage (78\% versus $56 \% ; P=.03)$. Ischemic frontal lobe infarction (OR, $2.9 ; 95 \% \mathrm{Cl}, 1.1-8.4 ; P=.03)$ and recurrent artery of Heubner infarction (OR, 20.9; 95\% Cl, 3.5-403.7; $P<.001$ ) were more common in clipped patients. Clipped patients were more likely to be functionally dependent at discharge (OR, 3.2; $P=.05)$ compared with coiled patients. Mortality and clinical outcome at 3 months were similar between coiled and clipped patients.

CONCLUSIONS: Frontal lobe and recurrent artery of Heubner infarctions are more common after surgical clipping of ruptured anterior communicating artery aneurysms, and are associated with poorer clinical outcomes at discharge.

ABBREVIATIONS: AcomA = anterior communicating artery aneurysm; RAH = recurrent artery of Heubner; HHS = Hunt and Hess Scale

S ubarachnoid hemorrhage secondary to rupture of a cerebral aneurysm affects 30,000 people in the United States every year and results in significant morbidity and mortality. ${ }^{1}$ Clinical outcomes after aneurysm rupture and treatment are influenced by cumulative cerebral infarction burden. ${ }^{2,3}$ Furthermore, patients who recover from aneurysm rupture are often left with disabling cognitive deficits that may result in the patient's dependency on others, which is reflect by higher mRS scores. ${ }^{4,5}$ The severity of

Received March 28, 2017; accepted after revision June 16

From the Department of Radiology, Neuroimaging and Neurointervention Division (J.J.H., N.A.T., H.M.D., M.W., M.P.M.), Department of Medicine, Quantitative Sciences Unit (R.L.B.), and Department of Neurosurgery (R.L.D., G.K.S., S.D.C.), Stanford University School of Medicine, Stanford, California.

Please address correspondence to Jeremy J. Heit, MD, PhD, 300 Pasteur Dr, Room S-047, Stanford, CA 94305; e-mail: jheit@stanford.edu; @JeremyHeitMDPHD

$\equiv$ Indicates article with supplemental on-line table.

Indicates article with supplemental on-line photos.

http://dx.doi.org/10.3174/ajnr.A5355 these cognitive deficits has been correlated to the Hunt and Hess Scale (HHS) grade on admission, older age, aneurysm location, and treatment-related brain injury. ${ }^{6-8}$

Anterior communicating artery aneurysms (AcomAs) are among the most commonly identified ruptured aneurysms, ${ }^{9,10}$ and AcomA rupture and treatment are more strongly associated with cognitive and behavioral deficits relative to other aneurysm locations. ${ }^{5,11-14}$ The cause of these neuropsychiatric deficits remains uncertain, but prior studies have suggested ischemic injury to the frontal cortex, ventromedial prefrontal (orbitofrontal) cortex, or striatum as a possible etiology. ${ }^{15-17}$

Ruptured aneurysms may be successfully treated by microsurgical clipping or endovascular coil embolization. ${ }^{5,9,18}$ However, surgical clipping of AcomAs has been associated with more severe cognitive and behavioral deficits and higher rates of patient dependency compared with endovascular coil embolization, which may be caused by retraction injury to the frontal lobe or other causes of cerebral infarction. . $^{2,11,13,14,17,19}$ 
Our primary aim was to determine whether there is an increase in frontal lobe or striatum ischemic injury after treatment with surgical clipping compared with coil embolization in patients with ruptured AcomA. Our secondary outcomes were patient mortality and clinical outcome at discharge and at 3 months of follow-up. We therefore characterized patterns of cerebral ischemic injury and patient outcomes after treatment of ruptured AcomA at our neurovascular referral center.

\section{MATERIALS AND METHODS \\ Patient Information}

The study was approved by our institutional review board and complied with the Health Insurance Portability and Accountability Act. We retrospectively reviewed our radiology data base and medical records to identify consecutive patients who presented with SAH caused by AcomA rupture between January 2010 and December 2014. The patient flow in this study is summarized in On-line Fig 1. Patient demographic, treatment, and outcome data were determined by electronic medical record review. A good clinical outcome was defined as an mRS score of 2 or less, and mRS scores were documented in the electronic medical record.

\section{Image Acquisition and Analysis}

Head NCCT and CTA were performed in all patients with standard protocols by using a 64-section helical CT scanner (LightSpeed; GE Healthcare, Milwaukee, Wisconsin). Axial NCCT images were obtained with $120 \mathrm{kVp}, 170 \mathrm{~mA}$, and 5-mm section thickness reconstruction. MR imaging and MRA were performed in 49 patients on a $1.5 \mathrm{~T}$ or $3 \mathrm{~T}$ scanner (Signa; GE Healthcare) by using standard departmental and vendor protocols. DSA was performed in all patients in a biplane neuroangiography suite (Axiom Artis; Siemens, Erlangen, Germany). Selective angiography of the bilateral internal carotid arteries and at least 1 vertebral artery was performed. AcomA coiling was performed after femoral artery access with general anesthesia and neurophysiologic monitoring. DSA was not performed before treatment technique decisions in all patients, and treatment decisions were at the discretion of the admitting neurosurgeon.

All CT, MR imaging, and DSA images were independently reviewed in a blinded manner by 3 interventional neuroradiologists with 2, 3, and 30 years of experience. Aneurysm size was determined by $3 \mathrm{D}$ rotational angiography when available or by CTA with 3D reformations. Follow-up studies were performed at various time points after endovascular or surgical treatment of the ruptured AcomA and ranged from postoperative day 0-159, with $80 \%$ performed within 2 days and 95\% performed within 5 days. If follow-up head imaging was not performed because of an excellent clinical status (no symptoms other than a mild headache), the patient was excluded from the subsequent imaging analysis. The presence of SAH, intraparenchymal hemorrhage, and intraventricular hemorrhage was noted on each study. Cerebral infarction was defined as new hypoattenuation on CT, restricted diffusion on MR imaging, or confluent T2 signal abnormality on MR imaging performed after treatment. Cerebral infarction secondary to vasospasm was defined as new hypoattenuation on $\mathrm{CT}$, restricted diffusion on MR imaging, or confluent T2 signal abnormality on MR imaging on subsequent studies when severe vaso- spasm was identified on an accompanying CTA, MRA, or DSA. Cerebral infarction was considered to be within the recurrent artery of Heubner (RAH) vascular territory if the infarction involved the caudate head with possible extension into the ipsilateral anterior limb of the internal capsule and/or medial lentiform nucleus. Other areas of cerebral infarction were also recorded.

\section{Outcomes}

The primary outcome was the frequency of frontal lobe and striatum ischemic infarction before discharge. Patients who did not receive imaging were not included in the primary analysis, but a sensitivity analysis was completed that included these patients (see "Statistical Analysis" section for details). Secondary outcome measures included patient mortality, clinical outcome at discharge, and clinical outcome at 3 months.

\section{Statistical Analysis}

Differences in patient demographics, clinical presentation, and aneurysm characteristics between the clipped and coiled groups were assessed with either the 2-sided Wilcoxon rank sum test for continuous characteristics or the 2-sided Fisher exact test for categoric characteristics; significance was assessed at the .05 level. To account for the nonrandom assignment to treatment, propensity scores were calculated with a multivariable logistic regression model with treatment as the response, and explanatory variables included demographic and other characteristics at presentation that were significantly different between treatment groups. ${ }^{20}$

Differences between treatments in primary and secondary outcomes were tested with the likelihood ratio test, where the restricted model included only the intercept and propensity score and the full model included the intercept, propensity score, and treatment; significance was assessed at the .05 level. Odds ratios were calculated as the odds of the outcome when clipping was applied divided by the odds of the outcome when coiling was applied after correcting for the nonrandom assignment to treatment by the propensity score. Analyses on outcomes were completed on data where the outcome was known, and if outcomes were missing, the number of missing values was noted. Because imaging to evaluate possible infarction was not performed on patients who had excellent clinical status, we completed a sensitivity analysis on the primary outcome of infarction that assumed patients with no imaging had not experienced an infarction. All analyses were completed in the statistical software $\mathrm{R}$ (http://www.r-project.org/). ${ }^{21}$

\section{RESULTS}

A total of 100 consecutive patients with ruptured AcomAs were identified, which coincidentally included 50 patients treated by microsurgical clipping ("clipped" patients) and 50 patients treated by coil embolization ("coiled" patients). Coiled patients were older (median age, 55 years compared with 50 years in the clipped group; $P=.03$ ), but there were no other significant differences with respect to sex, hypertension, hyperlipidemia, diabetes, coronary artery disease, smoking, illicit drug use, alcohol abuse, or a family history of aneurysms (Table 1). Clipped pa- 
Table 1: Patient demographic and presentation information

\begin{tabular}{lccc}
\hline & Clip & Coil & $P$ Value \\
\hline No. of patients & 50 & 50 & \\
Median age (IQR), yr & $50(41.00-58.00)$ & $55(48.00-63.75)$ & .03 \\
Female sex, no. (\%) & $26(52)$ & $31(62)$ & .42 \\
Hunt and Hess score, no. (\%) & & & .01 \\
$\quad 1$ & $6(12)$ & $2(4)$ & \\
2 & $27(54)$ & $18(36)$ & \\
3 & $14(28)$ & $16(32)$ & .69 \\
4 & $3(6)$ & $14(28)$ & .76 \\
Hypertension, no. (\%) & $31(62)$ & $28(56)$ & .72 \\
Diabetes mellitus, no. (\%) & $7(14)$ & $5(10)$ & .73 \\
Hyperlipidemia, no. (\%) & $12(24)$ & $16(32)$ & \\
Coronary artery disease, no. (\%) & $3(6)$ & $5(10)$ & 1 \\
Smoking status, no. (\%) & & & .68 \\
$\quad$ Never & $28(56)$ & $31(62)$ & 1 \\
$\quad$ Current & $19(38)$ & $15(30)$ & \\
$\quad$ Prior & $3(6)$ & $4(8)$ & \\
Drug use, no. (\%) & $5(10)$ & $2(4)$ & \\
Alcohol use, no. (\%) & $4(8)$ & $4(8)$ & \\
Family history of aneurysm, no. (\%) & $3(6)$ & & \\
\hline
\end{tabular}

Note:-IQR indicates interquartile range.

Table 2: Patient neuroimaging evaluation at presentation

\begin{tabular}{lccc}
\hline & Clip & Coil & $P$ Value \\
\hline No. of patients & 50 & 50 & \\
Modified Fisher score, no. (\%) & & & .01 \\
$\quad 0$ & $1(2)$ & $0(0)$ & \\
1 & $2(4)$ & $0(0)$ & \\
2 & $6(12)$ & $4(8)$ & \\
3 & $29(58)$ & $19(38)$ & .03 \\
4 & $12(24)$ & $27(54)$ & 1 \\
IVH, no. (\%) & $28(56)$ & $39(78)$ & .50 \\
Frontal lobe IPH, no. (\%) & $9(18)$ & $10(20)$ & .29 \\
Ischemic frontal lobe infarction, no. (\%) & $0(0)$ & $1(2.0)$ & .02 \\
Median aneurysm size (IQR), mm & $5.50(4.40-7.07)$ & $6.05(4.03-7.83)$ & .29 \\
Median aneurysm neck size (IQR), mm & $2.50(2.00-3.00)$ & $3.00(2.30-4.00)$ & \\
Median aneurysm ratio (IQR) & $2.10(1.50-2.70)$ & $2.00(1.70-2.30)$ & \\
\hline
\end{tabular}

Note:- IPH indicates intraparenchymal hemorrhage; IQR, interquartile range; IVH, intraventricular hemorrhage. the median size-to-neck ratio between clipped (2.1) and coiled (2.0) patients $(P=.29)$. These data are summarized in Table 2.

For the outcomes analysis, we calculated propensity scores (On-line Fig 2) for all patients by using a logistic regression model with probability of coiling as the response and covariates that included demographic and other characteristics at presentation that were significantly different between the treatment groups. The covariates analyzed included patient age, the HHS, modified Fisher grade, and intraventricular hemorrhage at presentation and aneurysm neck size.

Symptomatic vasospasm requiring endovascular treatment with intra-arterial nicardipine infusion and/or cerebral arterial angioplasty occurred in 25 patients (12 clipped and 13 coiled). After accounting for the propensity score, there was no significant difference $(P=$ .36) between treatments in patients requiring endovascular treatment of vasospasm. However, clipped patients ( 9 of 12 compared with 3 of 13 coiled patients) were more likely to require angioplasty for treatment of severe vasospasm (OR, 17.8; 95\% CI, 1.4-819.7; $P=.03)$. In a separate logistic regression analysis, endovascular vasospasm treatment was highly predictive of mortality tients presented with a more favorable clinical status as determined by the HHS $(P=.01)$.

Head CT upon presentation demonstrated higher modified Fisher grades in patients who subsequently underwent coiling $(P=.01$; Table 2$)$. Intraventricular hemorrhage was present in $67 \%$ of all patients and was present more frequently in coiled patients compared with clipped patients (39 patients [78\%] versus 28 patients $[56 \%] ; P=.03)$. Intraparenchymal hemorrhage was identified on presentation in 19 patients (19\%), and there was no difference $(P=1)$ in the frequency of intraparenchymal hemorrhage between those who were clipped (9 patients [18\%]) and coiled (10 patients [20\%]). A single patient who underwent coil embolization presented with an ischemic infarction in the left superior frontal gyrus, which was secondary to severe anterior cerebral artery vasospasm identified at the time of presentation. No other areas of ischemic infarction were identified on presentation head CT studies or imaging studies obtained before aneurysm treatment. These data are summarized in Table 2.

There was no significant difference in median maximal aneurysm diameter between clipped $(5.5 \mathrm{~mm})$ and coiled $(6.1 \mathrm{~mm})$ patients $(P=.29)$. Aneurysms treated by coiling had a larger median neck diameter of $3.0 \mathrm{~mm}$ compared with $2.5 \mathrm{~mm}$ in clipped patients $(P=.02)$. However, there was no difference in
(OR, 5.6; 95\% CI, 1.5-23.9; $P=.01$ ). All patients who required vasospasm treatment and survived (19 of 25 patients) were dependent $(\mathrm{mRS}>2)$ at discharge $(P=.001)$. Seven (of 19) patients who underwent vasospasm treatment improved by 3 months and were independent ( $\mathrm{mRS} \leq 2$ ), but vasospasm remained highly predictive of a poor outcome ( $\mathrm{mRS}>2)$ at 3-months (OR, 4.4; 95\% CI, 1.5-13.3; $P=.005)$.

Follow-up head CT or MR imaging was performed after AcomA clipping or coiling in 94 patients (94\%), including 46 clipped patients (92\%) and 48 coiled patients (96\%). Follow-up MR imaging was performed in 22 clipped patients (48\%) and 27 coiled patients $(56 \%)$. The 6 patients in whom follow-up imaging was not obtained each had an excellent clinical status and were symptom-free after treatment. On follow-up imaging, intraparenchymal hemorrhage was present in 12 of 46 clipped patients (26\%, compared with 9 patients on presentation imaging) and 11 of 48 coiled patients ( $23 \%$, compared with 10 patients on presentation imaging), but these differences were not significant $(P=$ $.06)$. This increased frequency of intraparenchymal hemorrhage was caused by hemorrhage related to extraventricular drain placement, aneurysm rerupture before treatment, or intraprocedural rupture during surgical clipping or endovascular coil embolization. These results are summarized in Table 3. 


\begin{tabular}{|c|c|c|c|c|}
\hline & Clip & Coil & OR $(95 \% \mathrm{CI})$ & $P$ Value \\
\hline No. of patients & 50 & 50 & & \\
\hline Patients without FU imaging, no. (\%) & $4(8)$ & $2(4)$ & & \\
\hline Frontal lobe IPH after treatment, no. (\%) ${ }^{\mathrm{a}}$ & $12(26.1)$ & $11(22.9)$ & $3.0(1.0-10.1)$ & .06 \\
\hline Nonvasospasm ischemic frontal lobe infarction, no. $(\%)^{a}$ & $12(26.1)$ & $2(4.2)$ & $8.5(1.9-62.3)$ & .004 \\
\hline Artery of Heubner infarction after treatment, no. $(\%)^{\mathrm{a}}$ & $15(32.6)$ & $1(2.1)$ & $20.9(3.5-403.7)$ & $<.001$ \\
\hline Embolic infarction after treatment, no. $(\%)^{\mathrm{a}}$ & $4(8.7)$ & $12(25)$ & $0.3(0.1-1.1)$ & .07 \\
\hline Vasospasm-related ischemic infarction, no. (\%) ${ }^{\mathrm{a}}$ & $7(15.2)$ & $8(16.7)$ & $0.9(0.3-3.1)$ & .85 \\
\hline Any ischemic infarction after treatment, no. $(\%)^{a}$ & $33(71.7)$ & $24(50)$ & $4.1(1.5-12.4)$ & .005 \\
\hline
\end{tabular}

Note:-FU indicates follow-up; IPH, intraparenchymal hemorrhage.

${ }^{a}$ Percentages refer to the number of patients with non-missing values ( 46 clip and 48 coil). $P$ values are from the likelihood ratio test using propensity scores and odds ratios, and resulting $95 \% \mathrm{Cls}$ are derived from the logistic model that includes both treatment and propensity scores (see "Materials and Methods" section).

Clipped patients had greater odds of experiencing any ischemic cerebral infarction when all types of infarction were considered (OR, 4.1; 95\% CI, 1.5-12.4; $P=.005)$. RAH territory ischemic infarction was more likely in clipped patients compared with coiled patients (OR, 20.9; 95\% CI, 3.5-403.7; $P<$.001) (Fig 1, Table 3). Clipped patients also had greater odds of ischemic frontal lobe infarction (OR, 8.5; 95\% CI, 1.9-62.3; $P=.004)$. There was a trend toward more frequent punctuate emboli infarctions in coiled patients, but this difference was not significant (OR, 0.3; $95 \% \mathrm{CI}, 0.1-1.1 ; P=.07)$. A sensitivity analysis that treated missing imaging as indicative of no infarction did not alter these conclusions except that intraparenchymal hemorrhage on follow-up was significantly associated with clipping (OR, 3.1; 95\% CI, 1.010.7; $P=.05$; On-line Table). To be thorough, we considered a less likely scenario and treated missing imaging as indicative of an infarction, but even this unlikely scenario did not alter the conclusions (On-line Table). There was no difference in the frequency of confluent arterial territorial infarction secondary to known vasospasm between clipped and coiled groups. These results are summarized in Table 3.

Secondary patient outcomes were mortality and, for those who survived to discharge, mRS at discharge and at 3 months (Table 4). There were 10 deaths before discharge, including 3 clipped patients $(6 \%)$ and 7 coiled patients (14\%), and no additional deaths occurred by 3 months. There was no difference in mortality between clipped and coiled patients (OR, 0.5; 95\% CI, $0.1-2.0 ; P=.31)$.

Among all patients at discharge, there were 13 coiled patients and 13 clipped patients with an $\mathrm{mRS} \leq 2$. When the propensity score was applied to a logistic regression model including all patients, there was no significant difference between the outcomes of clipped and coiled patients (OR, 3.0; 95\% CI, 1.0-10.1; P = .06). However, when we considered only patients who survived to discharge, we found that clipped patients were more likely to have a worse clinical outcome ( $\mathrm{mRS}>2$ ) at discharge compared with coiled patients (OR, 3.4; 95\% CI, 1.2-12.3; $P=.04$ ).

At 3-month follow-up, no additional deaths had occurred, and 16 patients ( 8 coiled, 8 clipped) were lost to follow-up, which left 74 patients ( 35 coiled and 39 clipped) for analysis (On-line Fig $1)$. Of these patients, 28 coiled patients $(80 \%)$ and 30 clipped patients $(77 \%)$ had a good clinical outcome (mRS $\leq 2)$. After baseline differences were accounted for by using a propensity score, we did not find any significant association between treatment choice and 3-month outcomes (OR, 2.1; 95\% CI, 0.6-8.0; $P=$.24).

\section{DISCUSSION}

Cerebral infarction is common after cerebral aneurysm rupture, ${ }^{22,23}$ and prior studies have correlated the cumulative burden of cerebral infarction to poor clinical outcome and cognitive outcomes. ${ }^{2,3}$ In this study, we questioned whether differences in cerebral infarction pattern and burden after treatment of ruptured AcomAs by clipping compared with coiling might account for differences in clinical outcome.

The frequency of cerebral infarction $(61 \%)$ in our study is in agreement with prior studies, which have described cerebral infarction rates ranging from $39 \%-87 \% .^{2,22,23}$ Similar to prior studies, we found increased cumulative cerebral infarct burden among patients with ruptured AcomA treated by microsurgical clipping ( $72 \%$ of patients) compared with those treated by endovascular coil embolization (50\% of patients). ${ }^{2,17}$ Moreover, the less frequent use of MR imaging in clipped patients may slightly underestimate the frequency of cerebral infarction in this group. The increased frequency of embolic infarction in patients undergoing endovascular coiling is not surprising, given that endovascular procedures are known to result in punctuate infarctions. However, these punctate infarctions are often clinically silent, and in this study, we found that the difference was not significant. ${ }^{24}$ These data suggest that the cumulative differences in cerebral infarction between clipped and coiled patients reflect the mode of treatment rather than the natural history of the ruptured AcomA.

We found cerebral infarction in the vascular distribution of the RAH to be significantly more common among patients treated with microsurgical clipping compared with endovascular coil embolization (OR, 20.9; 95\% CI, 3.5-403.7). A prior study found RAH territory infarction in $50 \%$ of patients with amnesia after AcomA clipping, but patients treated with endovascular coiling were not analyzed. ${ }^{25}$ Another study found RAH territory infarction in $15 \%$ of patients treated for AcomA by clipping compared with $2 \%$ for those treated by coiling, though patient outcomes related to these infarctions were not described. ${ }^{17} \mathrm{RAH}$ infarction causes injury to the medial and basal striatum, especially the caudate head, ${ }^{26}$ and memory dysfunction and behavioral deficits have been linked to caudate head infarction. ${ }^{12,15,16}$ The reason for this increased frequency of RAH infarction in patients with ruptured AcomAs treated by microsurgical clipping is not clear. The RAH may be stretched or injured in the setting of SAH because of AcomA rupture, the surgical clips may impinge upon the RAH, or vasospasm may be more likely to develop after surgical manipulation, which may result in RAH territory infarction. Postmortem analyses have found the anatomic course of the 

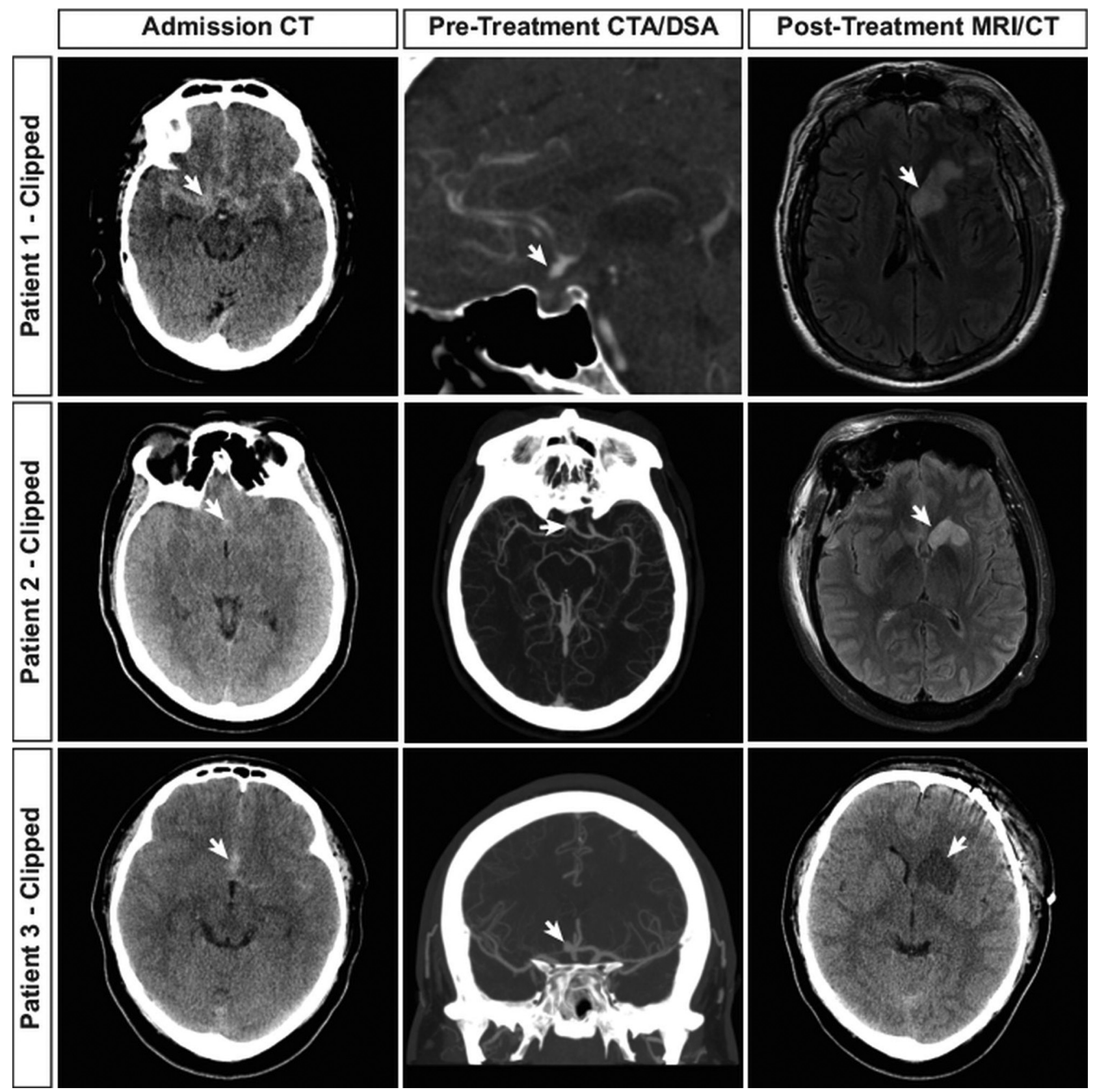

FIG 1. Recurrent artery of Heubner infarction in patients with ruptured AcomA treated by microsurgical clipping. Neuroimaging studies from 3 patients with ruptured AcomA treated by microsurgical clipping are shown. Admission head CT shows SAH (arrows, first column) as hyperattenuated blood in the subarachnoid space. Vascular imaging demonstrates the AcomA (arrows, second column) in each patient by CTA. Postclipping neuroimaging demonstrates cerebral infarction in the RAH territory (arrows, third column) by fluid-attenuated inversion recovery MR imaging (patients 1 and 2) or NCCT (patient 3).

Table 4: Clinical outcome in patients treated by aneurysm clipping versus coiling ${ }^{\text {a }}$

\begin{tabular}{|c|c|c|c|c|c|}
\hline & All, no. (\%) & Clip, no. (\%) & Coil, no. (\%) & OR $(95 \% \mathrm{CI})$ & $P$ Value \\
\hline No. of patients & $100(100)$ & $50(50)$ & $50(50)$ & & \\
\hline Mortality by discharge ( $n=100 ; 50$ clip, 50 coil) & $10(10)$ & $3(6.0)$ & $7(14.0)$ & $0.5(0.1-2.0)$ & .31 \\
\hline $\mathrm{mRS}>2$ at discharge $(n=100 ; 50$ clip, 50 coil $)$ & $74(74)$ & $37(74)$ & $37(74)$ & $3.0(1.0-10.0)$ & .06 \\
\hline Survivors' mRS $>2$ at discharge ( $n=90 ; 47$ clip, 43 coil) & $64(71.1)$ & $34(72.3)$ & $30(69.8)$ & $3.4(1.2-12.3)$ & .04 \\
\hline Survivors' mRS $>2$ at 3 months ( $n=74 ; 39$ clip, 35 coil) & $16(22)$ & $9(23.1)$ & $7(20.0)$ & $2.1(0.6-8.0)$ & .24 \\
\hline
\end{tabular}

a Percentages refer to the number of patients with non-missing values. $P$ values are from the likelihood ratio test using propensity scores and odds ratios, and resulting $95 \%$ confidence intervals are derived from the logistic model that includes both treatment and propensity scores (see "Materials and Methods" section).

RAH to be variable, which leads to additional challenges in the preservation of this artery during surgery. ${ }^{26,27}$

Frontal lobe ischemic infarction was also more common in clipped patients compared with coiled patients in our study (OR, 8.5; 95\% CI, 1.9-62.3). Prior studies have shown that cerebral infarction and encephalomalacia in the frontal lobes is more com- 
mon after clipping than coiling, ${ }^{2,17}$ which likely reflects a combination of retraction injury and ischemic stroke within the vascular territory of the anterior cerebral arteries and perforators that arise from the anterior communicating artery complex.

Similar to prior studies that have shown better clinical outcomes after endovascular treatment of ruptured aneurysms, ${ }^{18,28-30}$ we found that coiled patients were more likely to be discharged with an independent status ( $\mathrm{mRS} \leq 2)$. However, by 3 months of follow-up this difference in functional independence was no longer significantly different. The International Subarachnoid Aneurysm Trial showed that coil embolization of ruptured aneurysms results in higher rates of functional independence that lasts years after treatment, ${ }^{5,18}$ and our discrepant findings at 3 months most likely reflect the relatively small sample size of our cohort. We postulate that the better clinical outcomes among coiled patients in our study reflect the reduced rates of cerebral infarction, particularly within the frontal lobes and striatum.

Cognitive and behavioral deficits that result in poor clinical outcomes and reduced rates of functional independence are more common after AcomA rupture, 5,11,12 and AcomA treatment by microsurgical clipping is associated with more severe cognitive deficits compared with endovascular coil embolization. ${ }^{2,5,11,19}$ Similarly, surgical treatment of ruptured AcomAs is associated with a greater decline in perioperative Glasgow Coma Scale scores compared with endovascular coiling, ${ }^{31}$ but the reason for these differences remains unclear. Detailed neuropsychological testing after AcomA rupture and treatment is not routinely performed at our institution, which precludes correlating the degree and pattern of cerebral infarction to cognitive outcome in our series. However, many prior studies have now linked memory dysfunction and behavioral deficits to ischemic injury of the striatum, frontal lobe, and ventromedial prefrontal (orbitofrontal) cortex, ${ }^{2,3,15,16,32}$ and our analysis suggests that the higher burden of RAH territory and frontal lobe infarction may account for the worse cognitive outcomes associated with AcomA clipping. ${ }^{2,5,11,19}$ Future multicenter studies that include additional patients, detailed neuropsychologic testing, and neuroimaging studies should be performed to determine whether the higher rate of cerebral infarction in the striatum and frontal lobe after surgical treatment of ruptured AcomA accounts for worse cognitive and behavioral outcomes in these patients.

\section{Limitations}

This study is limited by its relatively small size, retrospective design, lack of randomization to clipping/coiling treatment, and single-center patient series, all of which may introduce selection bias. These biases may limit the generalizability of our findings despite our efforts to mitigate these biases with a propensity score in analyzing the outcomes. The posttreatment imaging analysis cannot be blinded to treatment type, given the different imaging appearance of the treatment modalities, which may introduce bias to the results. Moreover, $16 \%$ of patients were lost to follow-up at 3 months, which may limit the detection of differences in outcome between clipped and coiled patients at this time point. Neurocognitive testing is not routinely performed at our institution, and our study is limited in its inability to measure neurocog- nitive deficits that may have resulted from the patterns of infarction identified in this study.

\section{CONCLUSIONS}

Frontal lobe infarction and RAH infarction were more common after surgical clipping of ruptured AcomAs. Coiled patients had a better outcome at discharge and were more likely to be functionally independent than clipped patients. However, there were no differences in mortality or clinical outcome at 3 months between coiled and clipped patients. Further neuropsychological studies are warranted to determine whether postsurgical frontal lobe and RAH infarctions contribute to cognitive and behavioral deficits after ruptured AcomA treatment.

Disclosures: Jeremy Heit-UNRELATED: Consultancy: MicroVention, Comments: modest consulting fees with this company for work unrelated to cerebral aneurysm treatment; Employment: Stanford University, Comments: I am a practicing neurointerventionalist radiologist at Stanford, and I treat cerebral aneurysms as a part of my practice. Gary Steinberg-UNRELATED: Consultancy: Peter Lazic US Inc, Qool Therapeutics, Neurosave, Comments: serves in an advisory role for Peter Lazic US, Qool Therapeutics, and NeuroSave. Max Wintermark_UNRELATED: Board membership: GE NFL advisory board. Michael Marks_UNRELATED: Consultancy: Medtronic.

\section{REFERENCES}

1. Connolly ES Jr, Rabinstein AA, Carhuapoma JR, et al. Guidelines for the management of aneurysmal subarachnoid hemorrhage: a guideline for healthcare professionals from the American Heart Association/American Stroke Association. Stroke 2012;43:1711-37 CrossRef Medline

2. Hadjivassiliou M, Tooth CL, Romanowski CA, et al. Aneurysmal SAH: cognitive outcome and structural damage after clipping or coiling. Neurology 2001;56:1672-77 CrossRef Medline

3. Wong GK, Nung RC, Sitt JC, et al. Location, infarct load, and 3-month outcomes of delayed cerebral infarction after aneurysmal subarachnoid hemorrhage. Stroke 2015;46:3099-104 CrossRef Medline

4. Mayer SA, Kreiter KT, Copeland D, et al. Global and domain-specific cognitive impairment and outcome after subarachnoid hemorrhage. Neurology 2002;59:1750-58 CrossRef Medline

5. Molyneux AJ, Kerr RS, Yu LM, et al. International subarachnoid aneurysm trial (ISAT) of neurosurgical clipping versus endovascular coiling in 2143 patients with ruptured intracranial aneurysms: a randomised comparison of effects on survival, dependency, seizures, rebleeding, subgroups, and aneurysm occlusion. Lancet 2005;366:809-17 CrossRef Medline

6. Bornstein RA, Weir BK, Petruk KC, et al. Neuropsychological function in patients after subarachnoid hemorrhage. Neurosurgery 1987 ; 21:651-54 CrossRef Medline

7. Sonesson B, Ljunggren $B$, Säveland $H$, et al. Cognition and adjustment after late and early operation for ruptured aneurysm. Neurosurgery 1987;21:279-87 CrossRef Medline

8. Ljunggren B, Sonesson B, Säveland H, et al. Cognitive impairment and adjustment in patients without neurological deficits after aneurysmal SAH and early operation. J Neurosurg 1985;62:673-79 CrossRef Medline

9. Brisman JL, Song JK, Newell DW. Cerebral aneurysms. N Engl J Med 2006;355:928-39 CrossRef Medline

10. Heit JJ, Gonzalez RG, Sabbag D, et al. Detection and characterization of intracranial aneurysms: a 10-year multidetector CT angiography experience in a large center. J Neurointerv Surg 2016;8:1168-72 CrossRef Medline

11. Chan A, Ho S, Poon WS. Neuropsychological sequelae of patients treated with microsurgical clipping or endovascular embolization for anterior communicating artery aneurysm. Eur Neurol 2002;47: 37-44 CrossRef Medline

12. Martinaud O, Perin B, Gérardin E, et al. Anatomy of executive deficit 
following ruptured anterior communicating artery aneurysm. Eur J Neurol 2009;16:595-601 CrossRef Medline

13. Fontanella M, Perozzo P, Ursone R, et al. Neuropsychological assessment after microsurgical clipping or endovascular treatment for anterior communicating artery aneurysm. Acta Neurochir (Wien) 2003;145:867-72; discussion 872 CrossRef Medline

14. Proust F, Martinaud O, Gérardin E, et al. Quality of life and brain damage after microsurgical clip occlusion or endovascular coil embolization for ruptured anterior communicating artery aneurysms: neuropsychological assessment. J Neurosurg 2009; 110:19-29 CrossRef Medline

15. Mendez MF, Adams NL, Lewandowski KS. Neurobehavioral changes associated with caudate lesions. Neurology 1989;39: 349-54 CrossRef Medline

16. Mizuta $\mathrm{H}$, Motomura N. Memory dysfunction in caudate infarction caused by Heubner's recurring artery occlusion. Brain Cogn 2006; 61:133-38 CrossRef Medline

17. Mortimer AM, Steinfort B, Faulder K, et al. Rates of local procedural-related structural injury following clipping or coiling of anterior communicating artery aneurysms. J Neurointerv Surg 2016;8:256-64 CrossRef Medline

18. Molyneux A, Kerr R, Stratton I, et al. International Subarachnoid Aneurysm Trial (ISAT) of neurosurgical clipping versus endovascular coiling in 2143 patients with ruptured intracranial aneurysms: a randomised trial. Lancet 2002;360:1267-74 CrossRef Medline

19. Scott RB, Eccles F, Molyneux AJ, et al. Improved cognitive outcomes with endovascular coiling of ruptured intracranial aneurysms: neuropsychological outcomes from the International Subarachnoid Aneurysm Trial (ISAT). Stroke 2010;41:1743-47 CrossRef Medline

20. Austin PC. An introduction to propensity score methods for reducing the effects of confounding in observational studies. Multivariate Behav Res 2011;46:399-424 CrossRef Medline

21. R Development Core Team. R: A Language and Environment for Statistical Computing. Version 3.0.1. Vienna, Austria: R Foundation for Statistical Computing; 2013

22. Vilkki JS, Juvela S, Siironen J, et al. Relationship of local infarctions to cognitive and psychosocial impairments after aneurysmal subarachnoid hemorrhage. Neurosurgery 2004;55:790-802; discussion 802-03 CrossRef Medline

23. Rabinstein AA, Weigand S, Atkinson JL, et al. Patterns of cerebral infarction in aneurysmal subarachnoid hemorrhage. Stroke 2005; 36:992-97 CrossRef Medline

24. Krings T, Willmes K, Becker R, et al. Silent microemboli related to diagnostic cerebral angiography: a matter of operator's experience and patient's disease. Neuroradiology 2006;48:387-93 CrossRef Medline

25. Mugikura S, Kikuchi H, Fujii T, et al. MR imaging of subcallosal artery infarct causing amnesia after surgery for anterior communicating artery aneurysm. AJNR Am J Neuroradiol 2014;35:2293-301 CrossRef Medline

26. Zunon-Kipre Y, Peltier J, Haidara A, et al. Microsurgical anatomy of distal medial striate artery (recurrent artery of Heubner). Surg Radiol Anat 2012;34:15-20 CrossRef Medline

27. Maga P, Tomaszewski KA, Skrzat J, et al. Microanatomical study of the recurrent artery of Heubner. Ann Anat 2013;195:342-50 CrossRef Medline

28. Lanzino G, Murad MH, d'Urso PI, et al. Coil embolization versus clipping for ruptured intracranial aneurysms: a meta-analysis of prospective controlled published studies. AJNR Am J Neuroradiol 2013;34:1764-68 CrossRef Medline

29. Li H, Pan R, Wang H, et al. Clipping versus coiling for ruptured intracranial aneurysms: a systematic review and meta-analysis. Stroke 2013;44:29-37 CrossRef Medline

30. McDougall CG, Spetzler RF, Zabramski JM, et al. The Barrow Ruptured Aneurysm Trial. J Neurosurg 2012;116:135-44 CrossRef Medline

31. Ayling OG, Ibrahim GM, Drake B, et al. Operative complications and differences in outcome after clipping and coiling of ruptured intracranial aneurysms. J Neurosurg 2015;123:621-28 CrossRef Medline

32. Mavaddat N, Kirkpatrick PJ, Rogers RD, et al. Deficits in decisionmaking in patients with aneurysms of the anterior communicating artery. Brain 2000;123 (Pt 10):2109-17 CrossRef Medline 